\title{
STRESS AND LOAD DISTRIBUTION ANALYSIS IN BOLT CONNECTION WITH MODIFIED THREAD PROFILE UNDER HIGH TEMPERATURE CONDITIONS
}

\author{
LIANGE HE \\ School of Vehicle Engineering, Chongqing University of Technology, Chongqing, China, and \\ Key Laboratory of Advanced Manufacturing Technology for Automotive Components, Ministry of Education, Chongqing, \\ China, and Chongqing Tsingshan Industrial Co., Ltd., Chongqing, China \\ e-mail: heliange@cqut.edu.cn
}

BIN ZHANG

School of Vehicle Engineering, Chongqing University of Technology, Chongqing, China

CAIDONG GuO

Chongqing Zongshen Engine Manufacture Co., Ltd., Chongqing, China

Wenjun SHI

School of Vehicle Engineering, Chongqing University of Technology, Chongqing, China

\begin{abstract}
In this paper, the load distribution of a bolt connection structure with a variable thread profile at high temperature is investigated. The parameters of time-hardening creep model of aluminum alloy at high temperature were obtained by fitting the uniaxial creep tensile test data of aluminum alloy at $250^{\circ} \mathrm{C}$. Based on ABAQUS, a two-dimensional axisymmetric model of the bolt connection structure was established, and according to the thread load distribution considering linear elasticity, plasticity and creep characteristics, modification of standard metric thread profile was carried out. The load distribution law of the thread of the modified bolt connection structure were investigted. The results show that the load-bearing ratio of the first thread can be significantly reduced and the load-bearing distribution uniformity of all threads can be improved when the modified thread is applied to the bolt connection structure.

Keyword: bolt connection, thread design, load distribution of bolt, high temperature creep test, finite element analysis
\end{abstract}

\section{Introduction}

Bolt connection is one of the most commonly used components in engineering structures and mechanical design. Because of its simple structure, convenient disassemblement and low cost, it has been widely used, especially in many modern engineering structures (Hou and Liao, 2015). In a combined structure of bolt connection, due to structural characteristics of the connection, there are often problems such as stress concentration and uneven load distribution of thread teeth. The stress concentration mainly occurs at the thread root, especially at the first thread root, which affects strength and reliability of the bolt, connection to a certain extent (Chen et al., 2010; Farrahi et al., 2018). Xie et al. (2020) observed that when a bolted composite structure works in a high temperature environment, fluctuation of temperature and other environmental factors may affect its structural strength and reliability, resulting in bolt loosening and premature fatigue failure.

The cylinder head and cylinder block of an automobile engine are connected by bolts, and the reliability of the bolt connection directly affects the reliability of engine operation. The material 
of the engine cylinder head bolt is steel, and the connecting parts are usually made of aluminum alloy. Because the creep temperature of aluminum alloy is low, the use of aluminum alloy makes the bolt joint structure more prone to creep relaxation, which leads to premature failure of the bolt connection (Hashimura et al., 2019; An et al., 2011; Thoppul et al., 2009).

The bolt connection structure of the cylinder head is affected by a variety of environments in practical use, especially in high temperature. Material and mechanical properties of metal fasteners will change with temperature, which affects the performance of the bolt connection structure. In actual conditions, the maximum temperature of the cylinder head bolt is about $200-250^{\circ}$, and the maximum temperature of the cylinder head is about $200-300^{\circ} \mathrm{C}$. The creep of the steel material used in the engine cylinder head bolt occurs when the temperature is above $400-450^{\circ} \mathrm{C}$. Therefore, the creep can be omitted in calculation, but the creep of the aluminum alloy material used in the cylinder head must be considered (Zhang et al., 2003; Brown and Lim, 2017). In this paper, in view of the bolt connection combination structure, combined with mechanical design knowledge, the design of new thread for bolt connection is improved. This paper discusses the influence of different preloads on the load distribution of the thread of the improved bolt connection structure. Through the research of this paper, a new thread profile is designed, which will be better used in high temperature, and will improve reliability of the bolt connection structure to ensure reliability of the engine.

\section{Bolt connection combination structure}

The bolt connection structure is shown in Fig. 1. Among the loads of each thread, the load on the first thread tooth is the largest, and the load is mainly concentrated on the first three thread teeth. Hantouche et al. (2018), Welch (2018), Chen et al. (2017) showed that due to the influence of the material and bolt structure, stress concentration often occurs at the root of the thread, and the maximum stress is often found at the root of No. 1 thread.
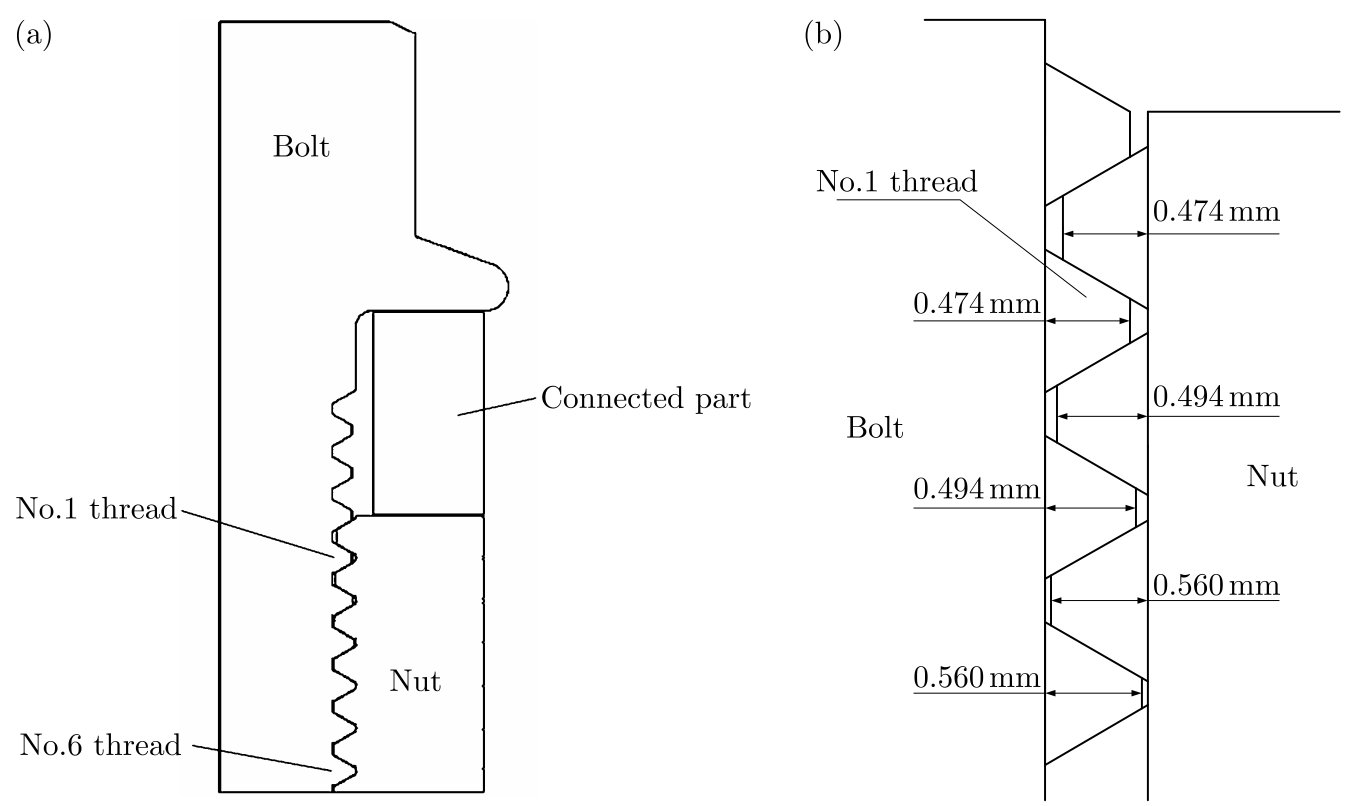

Fig. 1. Schematic diagram of the bolt connection structure

Since the load-bearing ratio of the thread teeth is mainly concentrated on the front three thread teeth, changing the contact area of the thread teeth can improve the uneven bearing of the bolt (Zhou et al., 2015; Zhao, 1996; Wang and Hu, 2017). So, this paper only designs the contact area of the front three thread teeth, and the other parameters of the thread teeth are 
unchanged. By reducing height of the thread to reduce the contact area of the thread, the load of the thread will be reduced, which will make the load of all threads more uniform. The details are as follows.

In this paper, we use M8 bolt, and 6 pairs of thread teeth contact. The average bearing ratio of the thread teeth is

$$
\bar{x}=\frac{1}{N} \sum_{i=1}^{N} x_{i}
$$

where $i$ is the number of the thread, $x_{i}$ is the load-bearing ratio of the thread $i$. Through the finite element calculation of the standard thread, the bearing ratio of the thread is obtained: $x_{1}=21.24 \%, x_{2}=20.34 \%, x_{3}=17.35 \% . N$ is the number of thread contact pairs.

The reduced thread height is

$$
\Delta H_{i}=\left(x_{i}-\bar{x}\right) H k
$$

where $H$ is height of the original thread; $k$ is the coefficient related to the height of the thread tooth $(k=3.86)$.

The thread height after the design modification is

$$
h_{i}=H-\Delta H_{i}
$$

The design is carried out with the results obtained in a plastic stage at normal temperature, and the results are shown in Table 1.

Table 1. Design dimensions of the variable thread teeth

\begin{tabular}{|c|c|c|c|}
\hline $\begin{array}{c}\text { Number of } \\
\text { thread }\end{array}$ & $\begin{array}{c}\text { Load bearing } \\
\text { ratio of thread }\end{array}$ & $\begin{array}{c}\text { Thread height before } \\
\text { modification }[\mathrm{mm}]\end{array}$ & $\begin{array}{c}\text { Thread height after } \\
\text { modification [mm] }\end{array}$ \\
\hline \hline 1 & $21.24 \%$ & 0.575 & 0.474 \\
\hline 2 & $20.34 \%$ & 0.575 & 0.494 \\
\hline 3 & $17.35 \%$ & 0.575 & 0.560 \\
\hline
\end{tabular}

The final design of the variable thread bolt connection structure is shown in Fig. 1.

\section{Determination of the creep model and its parameters}

\subsection{Creep model}

In this paper, the first and second stages of creep are studied. In order to better simulate the first and second stages of creep of metal materials, the most widely used time-hardening creep model is studied

$$
\dot{\varepsilon}_{c}=A \sigma^{n} t^{m}
$$

where $\dot{\varepsilon}_{c}$ is the equivalent creep strain rate; $\sigma$ is the test load; $t$ is the creep time; $A$ and $m$ are the creep test material constants; $n$ is the test stress index, which is used to characterize creep characteristics of materials. Taking the logarithm of both sides of formula (3.1), we get

$$
\ln \dot{\varepsilon}_{c}=\ln A+n \ln \sigma+m \ln t
$$

By creep test, the value of $n$ can be obtained for the creep rate in the second stage of creep under the same temperature and different stress. 
Since the creep test results show the relationship between the creep strain and time and the equivalent stress, it is necessary to integrate formula (3.1). The results are as follows

$$
\varepsilon_{c}=\frac{A}{m+1} \sigma^{n} t^{m+1}
$$

where $\varepsilon_{c}$ is the creep strain; $A$ and $n$ are greater than $0 ;-1<m<0$.

Using formula (3.3) to fit the creep strain curve obtained from the test, three parameters $A$, $m$ and $n$ can be obtained.

\section{2. $\quad$ Creep tensile test}

A uniaxial creep test of a unidirectional loading specimen is adopted in this creep test, and the creep material is aluminum alloy used for an engine cylinder head. The preparation of the test pattern and test method are carried out according to GB/T 2039-2012 (metal uniaxial tensile creep test method). The geometric dimension of the pattern is shown in Fig. 2, and the actual test piece is shown in Fig. 3 .

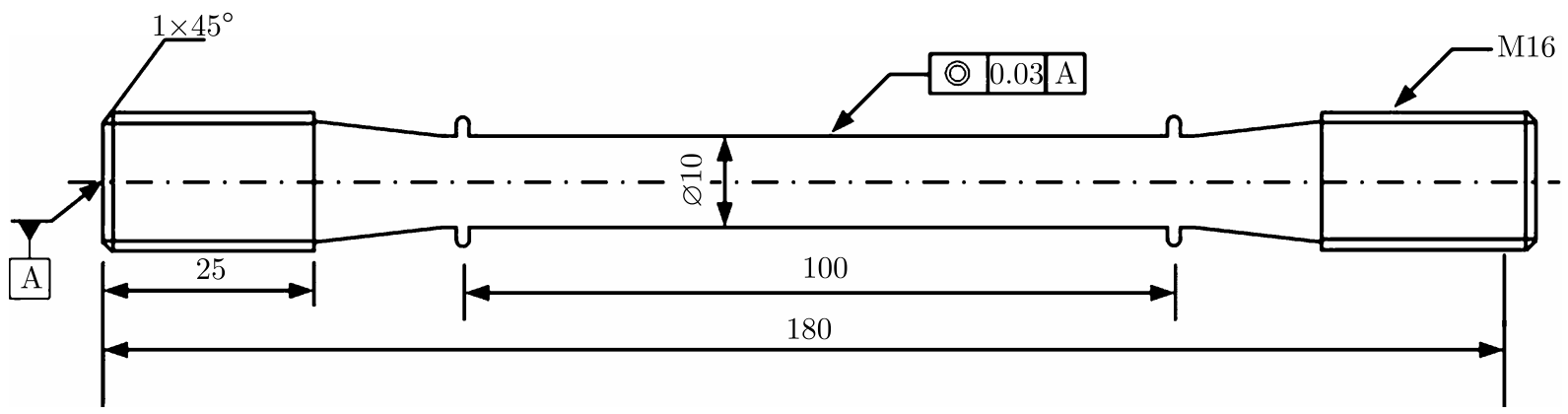

Fig. 2. Geometry of the high temperature creep test specimen

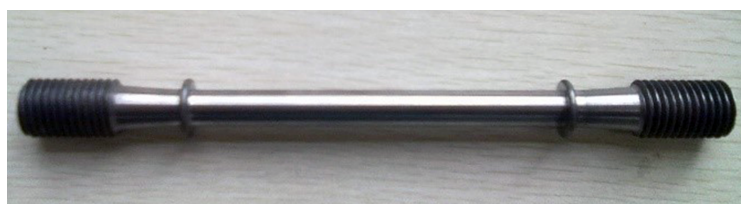

Fig. 3. Object of the high temperature creep test specimen

In order to explore the creep properties of aluminum alloy at high temperature, the test temperature was set at $250^{\circ} \mathrm{C}$. After the test temperature reaches the set temperature, it is kept for 2 hours, then a constant load to fracture or creep for 60 hours is applied, respectively. The creep strain data are recorded in real time. Figure 4 shows the creep test curve at $250^{\circ} \mathrm{C}$.

\subsection{Creep parameter fitting results}

Using formula (3.3) to fit the creep curves at different temperatures obtained from the creep test, the parameters of the creep damage formula at different temperatures are obtained, see Table 2 .

Table 2. Material parameters of the time-hardening creep model

\begin{tabular}{|c|c|c|c|}
\hline Temperature $\left[{ }^{\circ} \mathrm{C}\right]$ & $A$ & $m$ & $n$ \\
\hline \hline 250 & $1.935 \cdot 10^{-9}$ & $-5.380 \cdot 10^{-14}$ & 0.962 \\
\hline
\end{tabular}




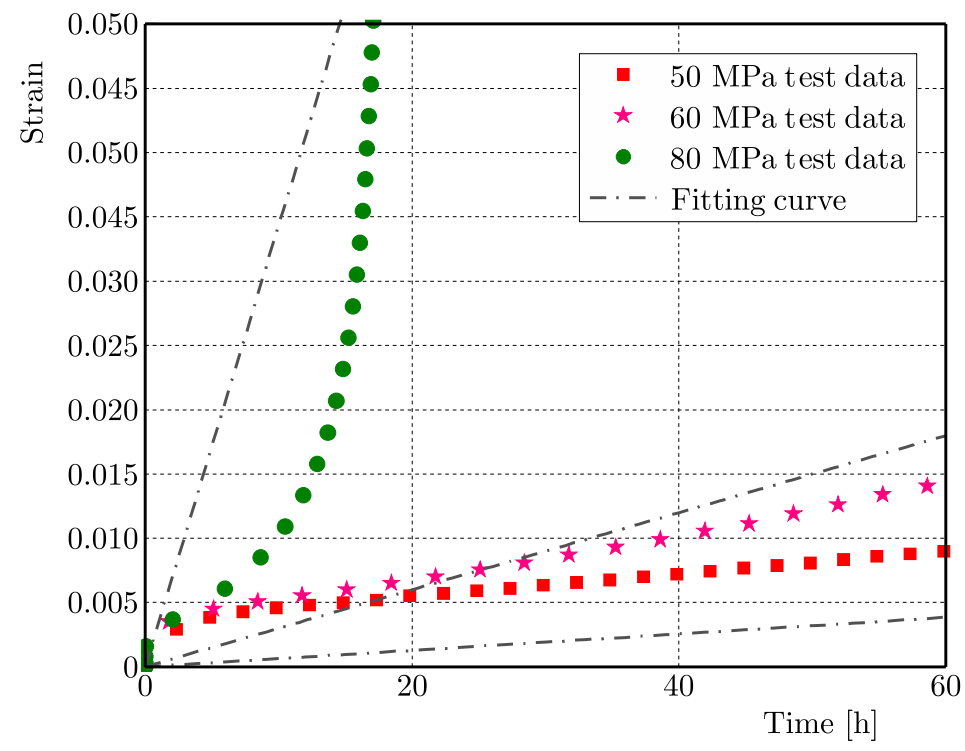

Fig. 4. Creep curve of aluminum alloy material at $250^{\circ} \mathrm{C}$

(a)

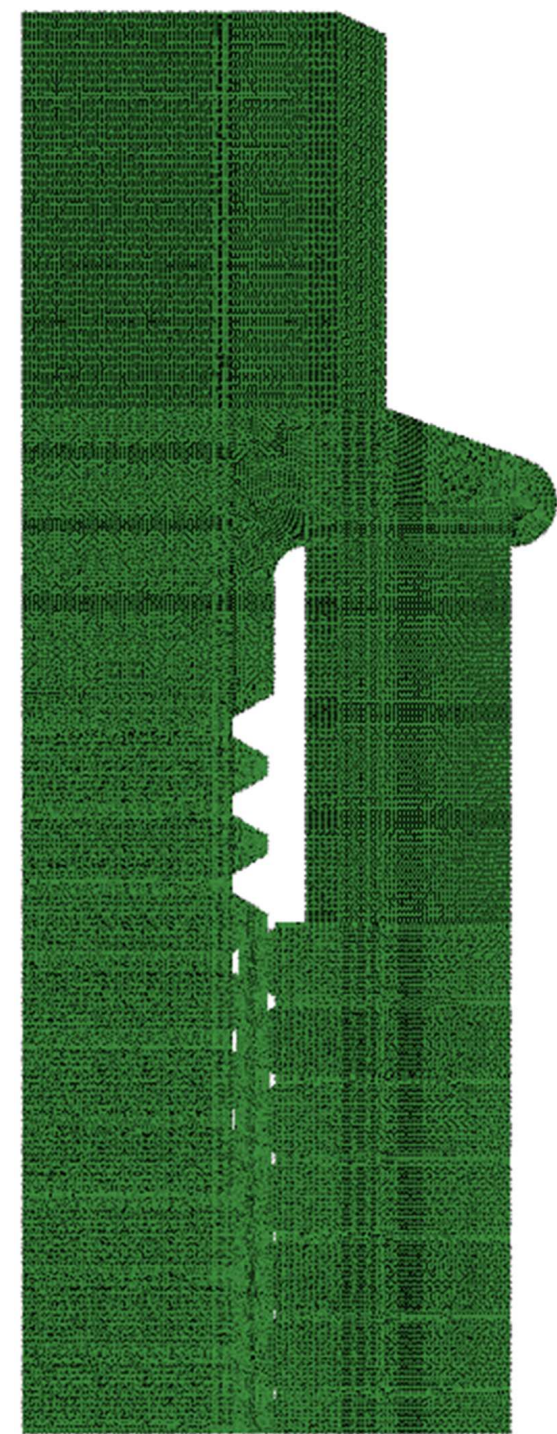

(b)

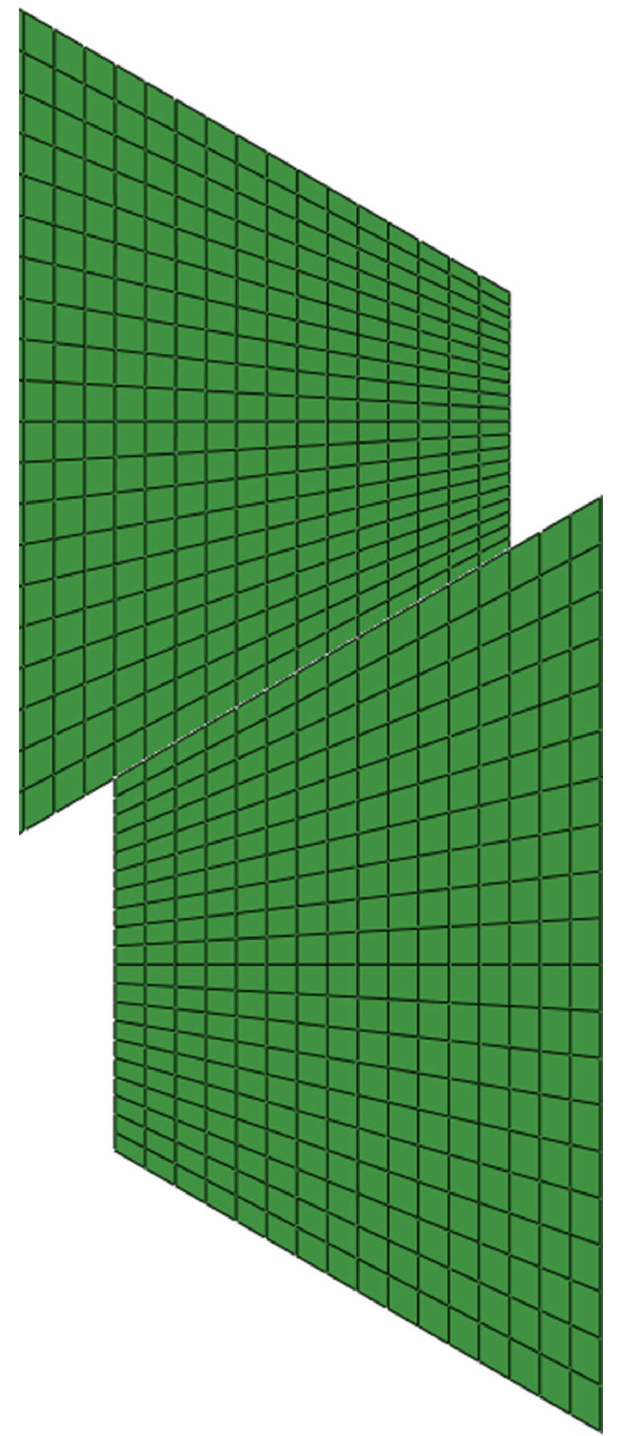

Fig. 5. Bolt connection structure finite element model: (a) bolt connection structure; (b) thread contact part 


\section{Finite element calculation of the bolt connection structure}

\subsection{Establishment of the finite element model}

According to Chen et al. (2010), considering the symmetry of the bolt connection structure, the simulation results of $2 \mathrm{D}$ and $3 \mathrm{D}$ models are basically consistent, which proves that the $2 \mathrm{D}$ axisymmetric model can be used for thread load calculation. Therefore, this paper adopts M8 bolt and simplifies the connection structure to the $2 \mathrm{D}$ axisymmetric model. Therefore, the mesh of the thread profile is refined, as shown in Fig. 5.

\subsection{Material properties}

In this paper, the finite element analysis is carried out by ABAQUS software. Based on the established bolt connection structure model, the influence of material linear elasticity, plasticity, creep characteristics and other factors on the load distribution of the threaded teeth is considered. Because the creep property of aluminum alloy is greatly affected by a temperature change, adding the creep property with the temperature change in the process of finite element calculation can more accurately simulate the load-bearing situation of the bolted composite structure at different temperatures.

The bolt is made of steel, and the material properties are shown in Table 3 . The connected parts are made of aluminum alloy, and the material properties are shown in Table 4 . The stress-strain curves of the two materials are shown in Figs. 6a and 6b.

Table 3. Stell material properties

\begin{tabular}{|c|c|c|c|}
\hline $\begin{array}{c}\text { Temperature } \\
{\left[{ }^{\circ} \mathrm{C}\right]}\end{array}$ & $\begin{array}{c}\text { Elastic modulus } \\
{[\mathrm{GPa}]}\end{array}$ & $\begin{array}{c}\text { Poisson's ratio } \\
{[-]}\end{array}$ & $\begin{array}{c}\text { Coefficient of linear } \\
\text { expansion }\left[{ }^{\circ} \mathrm{C}^{-1}\right]\end{array}$ \\
\hline \hline Normal temperature & 209 & 0.3 & $1.159 \cdot 10^{-5}$ \\
\hline 250 & 199 & 0.3 & $1.232 \cdot 10^{-5}$ \\
\hline
\end{tabular}

Table 4. Aluminum alloy material properties

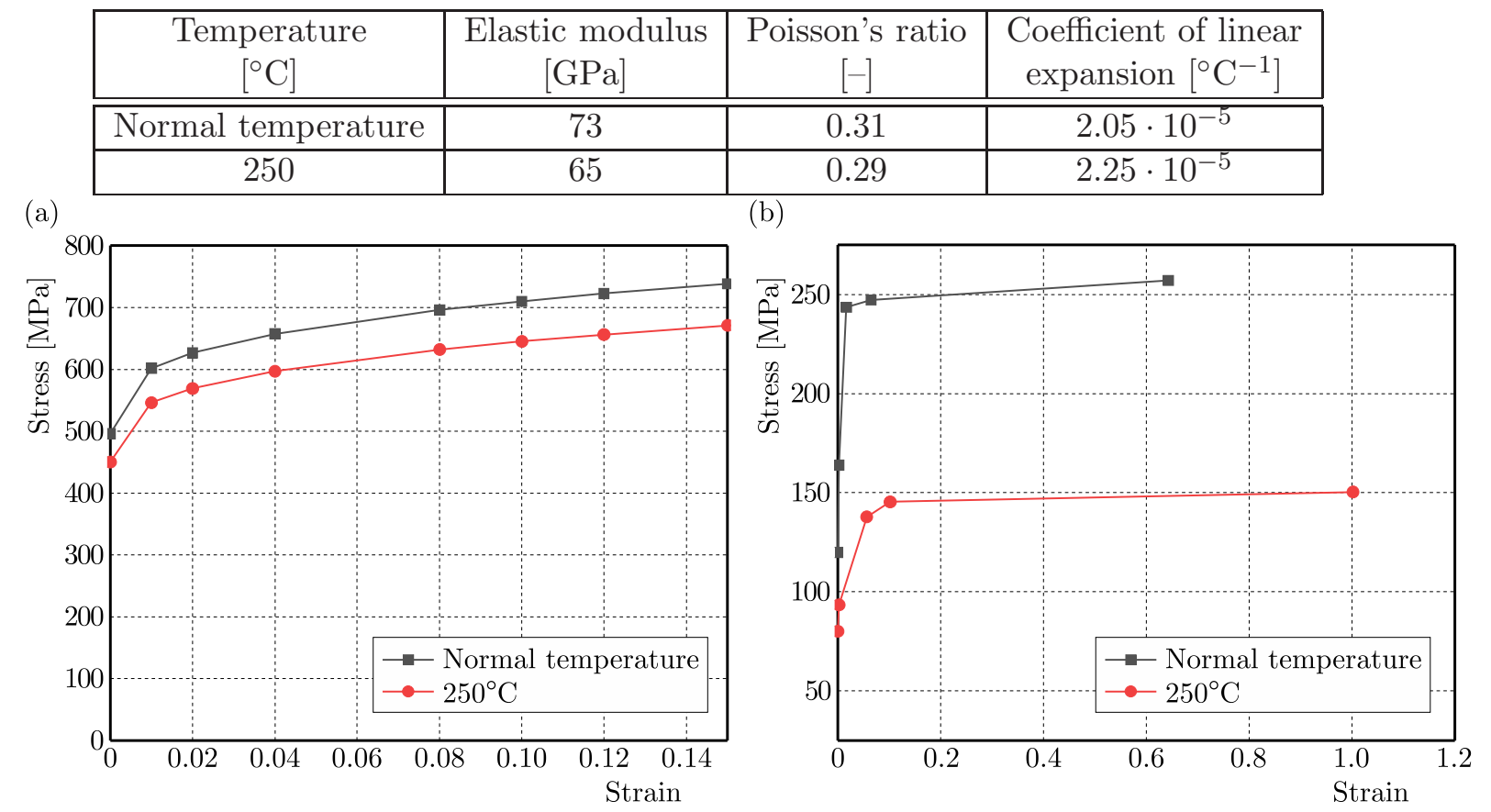

Fig. 6. Stress-strain curves of (a) steel materials and (b) aluminum alloy materials 


\subsection{Contact surface setting}

The contact properties of the threaded pair (including normal contact property and tangential friction property) are defined, and the upper and lower contact surfaces of the thread teeth are contacted. According to Housari and Nassar (2007), the influence of the friction coefficient of the thread and contact surface on self-loosening of bolted connection under transverse load is studied, and the friction coefficient between the contact surfaces of the bolted connection assembly structure is set as 0.15 . The contact pair chooses the surface with larger stiffness as the main surface, and the surface with smaller stiffness as the secondary surface. Because the relative sliding between the contact surfaces is very small, the small sliding contact is adopted.

\subsection{Boundary conditions and load application}

The boundary conditions are applied to the bolt axis to restrict the lateral displacement of all nodes on the axis, and the fixed constraints are applied to the bottom of the thread to restrict the axial displacement of all nodes at the bottom. A $5000 \mathrm{~N}$ axial load is applied to the bolt. The creep time is set to 10 hours.

\section{Analysis of the results of finite element calculation}

\subsection{Comparison of analysis results of the bolt joint combination structure before and after modification at room temperature}

Figure 7 shows the comparison of Huber-Mises-Hencky stress distribution before and after the new design of the thread teeth. From Figs. 7a and 7b, it can be seen that the maximum equivalent stress of the bolt joint composite structure before the improvement design is $400.1 \mathrm{MPa}$, and the maximum equivalent stress is $365.6 \mathrm{MPa}$. From Figs. 7c and $7 \mathrm{~d}$, it can be seen that the maximum equivalent stress of the bolt joint composite structure before the improvement design is $394.3 \mathrm{MPa}$, and the maximum equivalent stress is $361.1 \mathrm{MPa}$. It is shown that the improved thread teeth can reduce the maximum equivalent stress of the bolt joint structure and reduce stress concentration, which is conducive to improve the reliability of the bolt joint structure. This is because the modified height of the first three thread thread is reduced, which reduces the contact area of the front three thread teeth, and reduces the load on the front three thread teeth. At the same time, the stress concentration is greatly affected by structural deformation. When the material is in the plastic stage, deformation between the contact surfaces of the thread teeth will be intensified, which makes the stress concentration change suddenly in the place where the deformation occurs, and the stress concentration degree decreases.

Figure 8 shows the comparison before and after modification of the thread at normal temperature. It can be seen from the figure that the load-bearing ratio of the first thread of the modified thread decreases, the load-bearing ratio of the first thread in the elastic stage decreases from $23.81 \%$ to $21.88 \%$, and the load-bearing ratio of the first thread in the plastic stage decreases from $23.22 \%$ to $21.33 \%$. The load-bearing ratio of the last four threads increases, which means that the load-bearing distribution of the modified thread is more uniform, which proves that the modified thread can effectively improve uniformity of the load-bearing distribution of the thread.

\subsection{Comparison of analysis results of the bolt connection structure before and after modification at $250^{\circ} \mathrm{C}$}

Figure 9 shows the Huber-Mises-Hencky stress distribution of the bolt connection structure before and after modification at $250^{\circ} \mathrm{C}$. It can be seen that the maximum equivalent stress in the elastic stage before modification is $397.1 \mathrm{MPa}$; the maximum equivalent stress in the plastic 
(a)

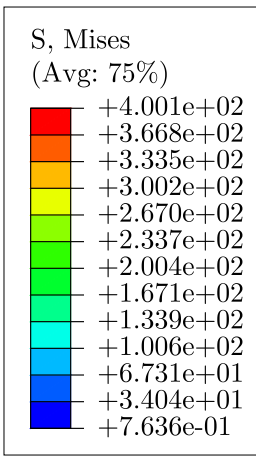

(c)

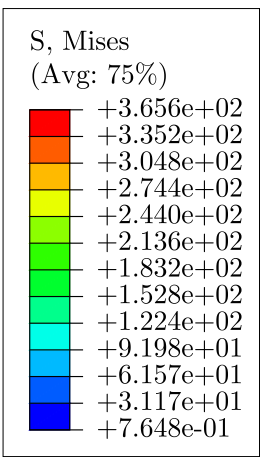

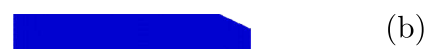

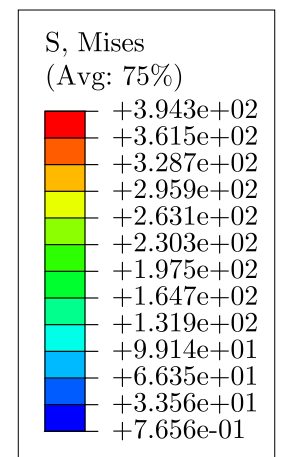

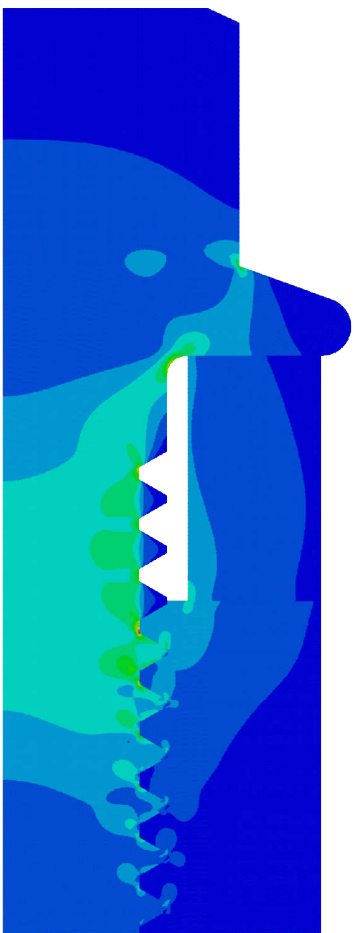

(d)

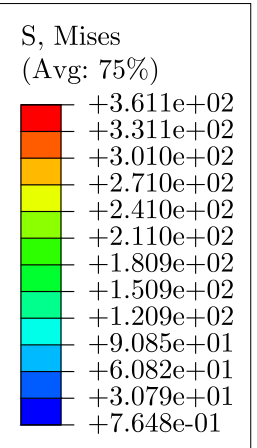

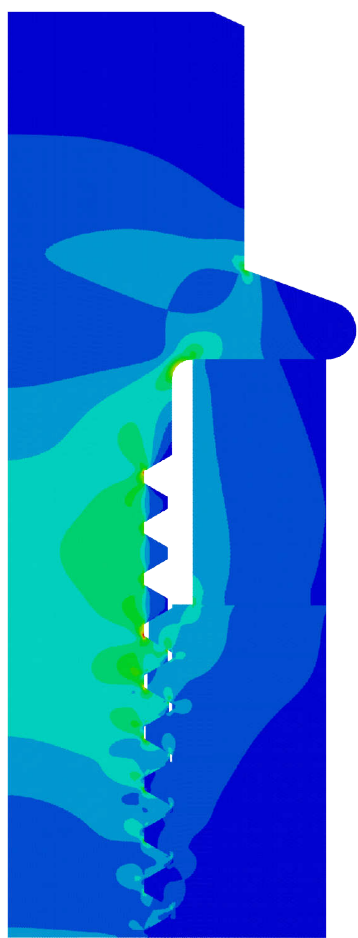

Fig. 7. Huber-Mises-Hencky stress distribution of the bolt connection structure before and after modification at normal temperature: (a) elastic stage before modification, (b) plastic stage before modification, (c) elastic stage after modification, (d) plastic stage after modification

stage is $359.7 \mathrm{MPa}$; and the maximum equivalent stress in the creep stage is $288.4 \mathrm{MPa}$. After modification, the maximum equivalent stress is $363.6 \mathrm{MPa}$ in the elastic stage, $340.8 \mathrm{MPa}$ in the plastic stage and $395.6 \mathrm{MPa}$ in the creep stage. The maximum equivalent stress appears at the root of the first thread in the elastic and plastic stages, and at the top of the first thread in the creep stage after modification. Compared with that before modification, in the elastic and 
(a)

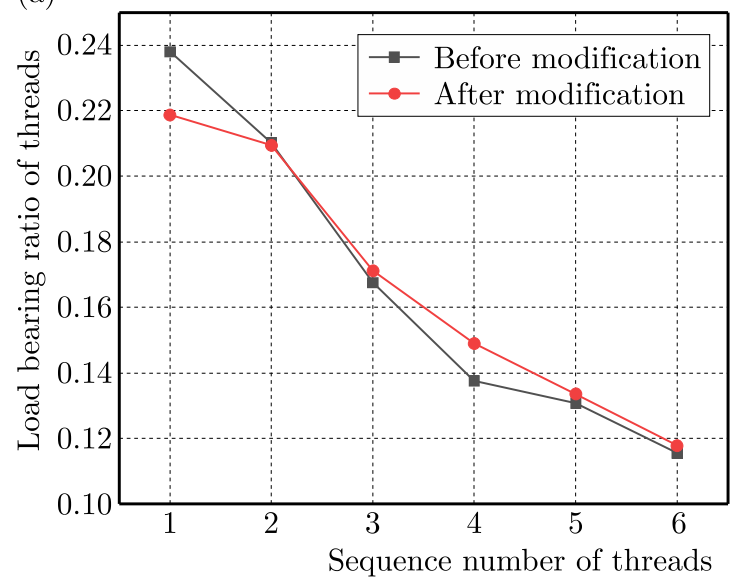

(b)

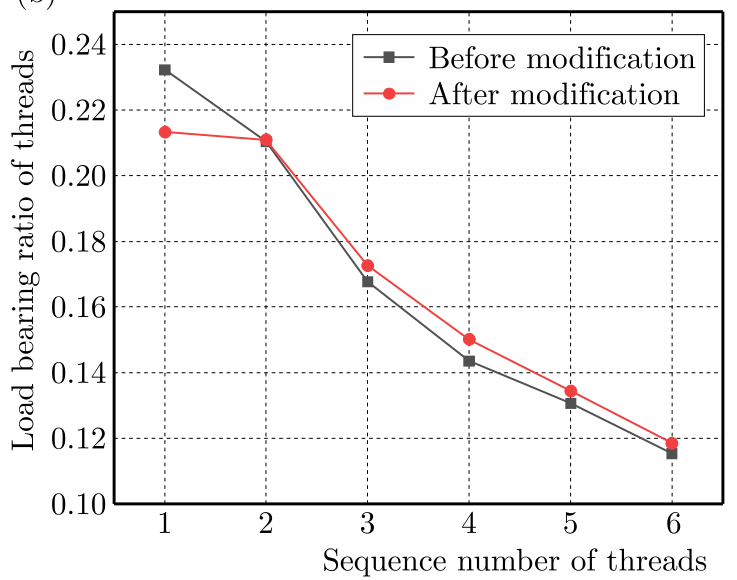

Fig. 8. Load distribution of the bolt connection structure before and after modification at normal temperature: (a) elastic stage, (b) plastic stage

plastic stages, the maximum equivalent stress decreases after modification. When the material is in the creep stage, the maximum equivalent stress increases greatly. This is because the stress concentration is largely affected by structural deformation. When the material is in the creep stage, the height of the first tooth is reduced, and the deformation will be reduced, so the stress concentration phenomenon will be more obvious. Although the maximum stress of the modified bolt is larger, the maximum stress does not exceed the yield stress of the bolt, and the modified thread tooth bearing is more uniform, which indicates that the modified bolt bearing capacity has been improved.

Figure 10 shows the load distribution of the thread before and after modification at $250^{\circ} \mathrm{C}$. It can be seen from Fig. 10a that in the elastic stage, the load-bearing ratio of the first thread and the second thread before modification is $23.36 \%$ and $20.86 \%$, respectively, and the load-bearing ratio of the first and second thread after modification is $21.50 \%$ and $20.90 \%$, respectively. The load-bearing ratio of the last thread after modification is increased, and the load-bearing ratio of all threads is increased. Examples are more focused. This shows that the load distribution of the thread will be more uniform in the elastic stage of the modified bolt connection at $250^{\circ} \mathrm{C}$.

It can be seen from Fig. 10b that in the plastic stage, the load-bearing ratio of the first thread and the second thread before modification is $20.44 \%$ and $20.96 \%$, respectively, and the loadbearing ratio of the first and second thread after modification is $18.41 \%$ and $20.41 \%$, respectively. The load-bearing ratio of the last thread after modification is increased, and the load-bearing ratio of all threads is more concentrated. This shows that the load distribution of the thread is more uniform in the plastic stage of the modified bolt connection at $250^{\circ} \mathrm{C}$.

It can be seen from Fig. 10c that in the creep stage, the load-bearing ratio of the first thread and the second thread before modification is $20 \%$ and $20.58 \%$, respectively, and the load-bearing ratio of the first and second thread after modification is $16.39 \%$ and $19.31 \%$, respectively. The load-bearing ratio of the last thread after modification is increased, and the load-bearing ratio of all threads is more concentrated. This shows that the load distribution of the thread is more uniform in the creep stage of the modified bolted connection at $250^{\circ} \mathrm{C}$.

When the bolted composite structure is at high temperature, the plastic and creep characteristics have a great influence on the load-bearing capacity of the thread, and the higher the temperature is, the more obvious this influence is. It can be seen from Figs. 10b and 10c that in the plastic and creep stage, the load-bearing ratio of the first thread greatly decreases, and more load will be transferred to the later thread, especially in the creep stage. This is be- 
(a)

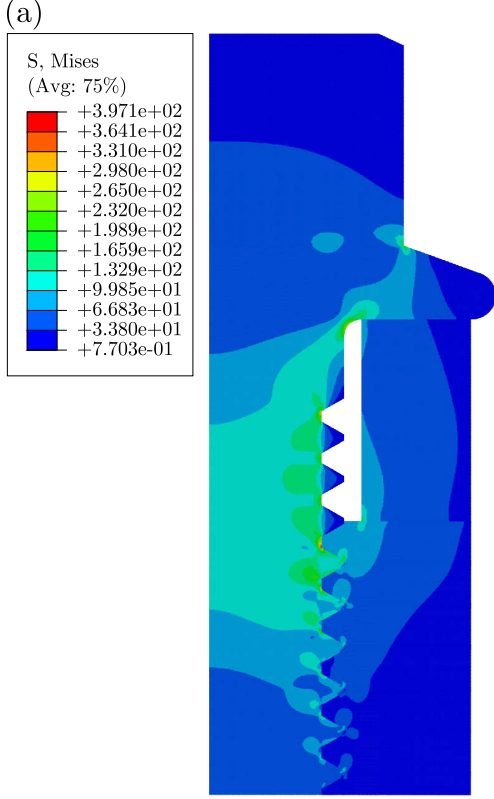

(d)
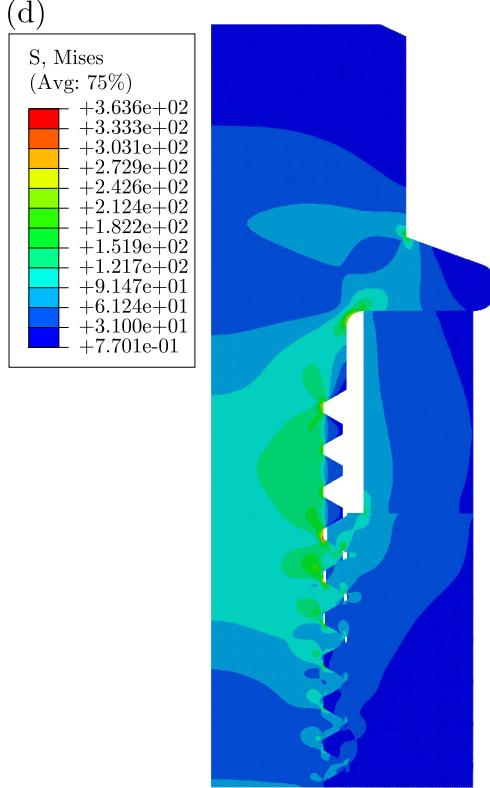

(b)
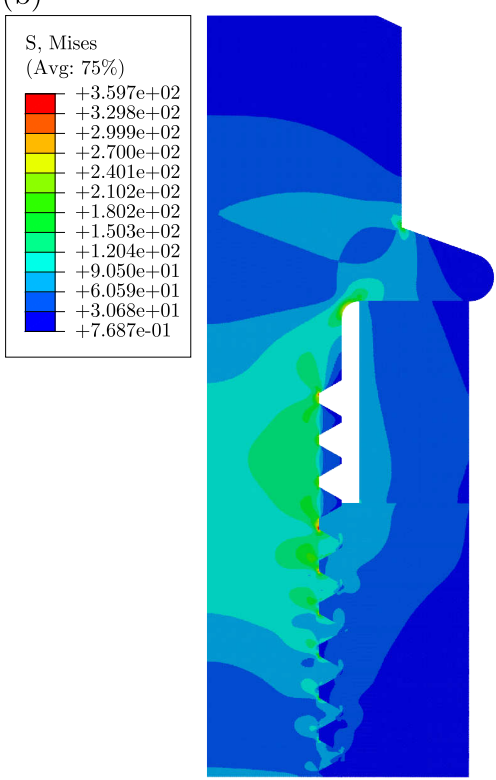

(e)

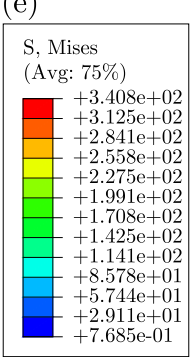

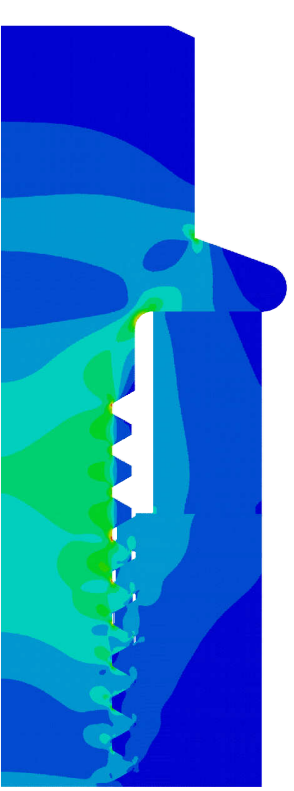

(c)
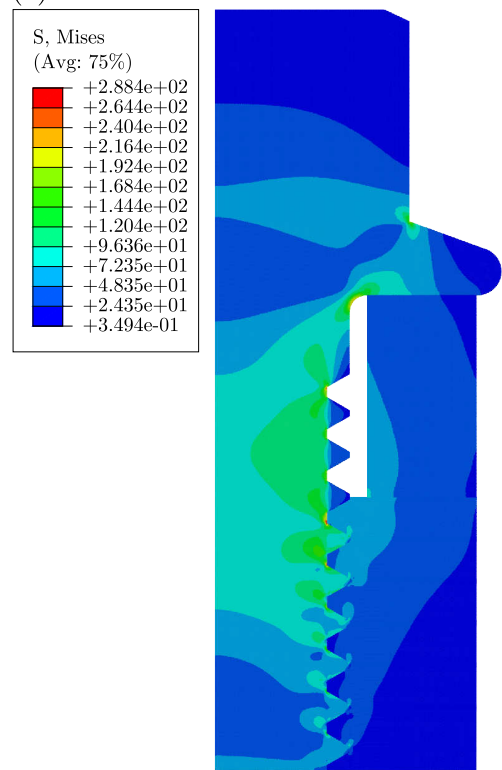

(f)
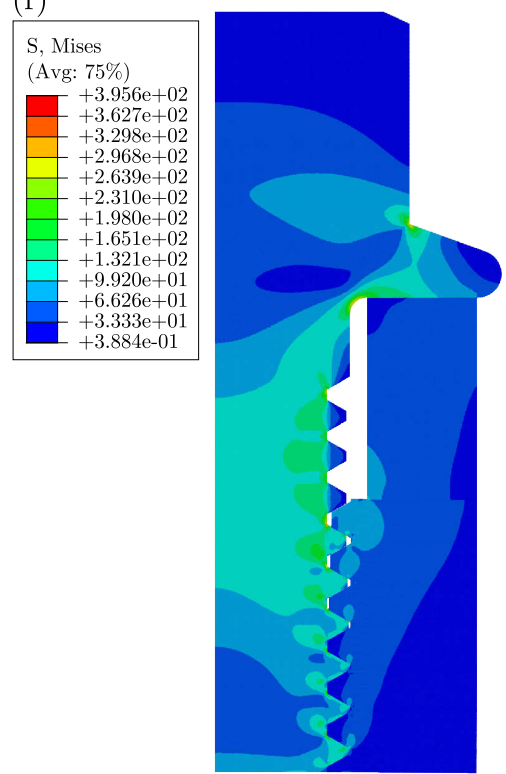

Fig. 9. Huber-Mises-Hencky stress distribution of the bolt connection structure after modification at $250^{\circ} \mathrm{C}$ : (a) elastic stage before modification, (b) plastic stage before modification, (c) creep stage

before modification, (d) elastic stage after modification, (e) plastic stage after modification,

(f) creep stage after modification

cause the modified height of the first three threads is reduced, and the contact area of the first three threads is reduced, so that the load-bearing ratio of the first three threads is reduced, and the load is transferred to the last few threads, so that the load distribution of all threads is more uniform. Because the material properties are affected by temperature, the higher the temperature, the smaller the yield strength of the material, which makes the first three threads easier to deform, resulting in a reduction of the contact area between the thread contact pairs and the corresponding bearing ratio. At the same time, the creep characteristics of the material also exhibit thread creep deformation, which makes this phenomenon more obvious. Because the additional bending moment makes the last thread contact more close, the last thread increases. 
(a)

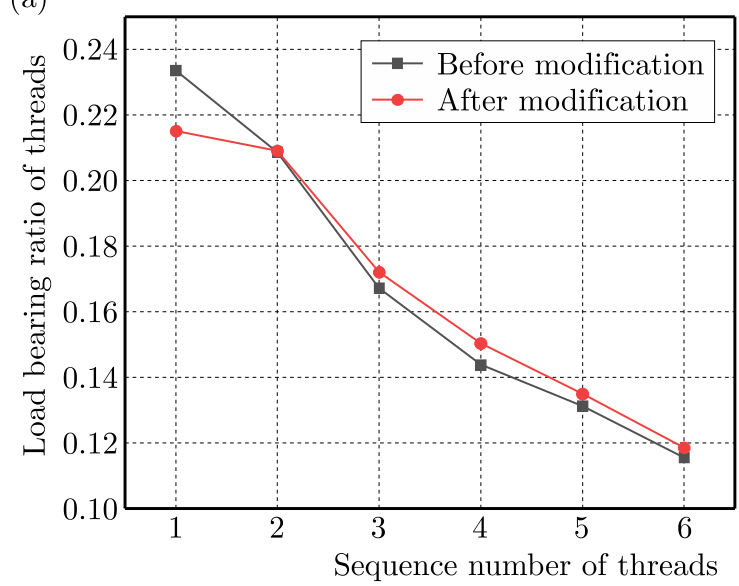

(b)

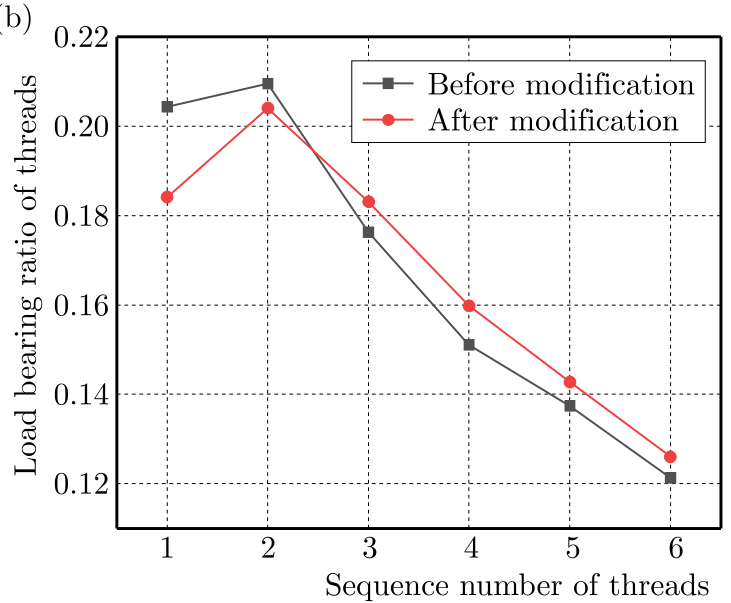

(c)

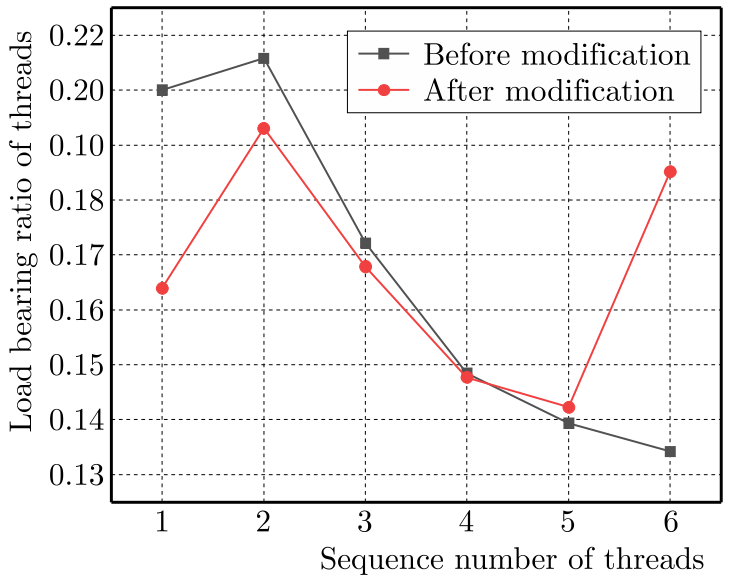

Fig. 10. Load distribution of the bolt connection structure after modification at $250^{\circ} \mathrm{C}$ : (a) elastic stage, (b) plastic stage, (c) creep stage

\section{Conclusion}

In this paper, a new bolt connection structure is designed based on the load distribution of the structure. The validity of the solution is verified by finite element analysis. The main conclusions are summarized as follows:

- The modified bolt connection structure can reduce stress concentration in the elastic and plastic stage, which is conducive to improve the reliability of the bolt joint structure.

- The modified bolt connection structure is designed, and the load distribution of the thread teeth is more uniform considering the plastic and creep characteristics of the material.

- For the modified bolt connection structure, the load distribution uniformity of the thread teeth is improved at normal temperature and $250^{\circ} \mathrm{C}$.

- In the creep stage, the maximum stress of the modified bolt is larger than that before, but the maximum stress does not exceed the yield stress of the bolt, and the modified thread tooth bearing distribution is more uniform.

\section{Acknowledgment}

The present research was supported by the China Postdoctoral Science Foundation funded project (grant No: 2019M663443); the youth project of science and technology research program of Chongqing Education Commission of China (grant No: KJQN201901113); the Open Foundation of Key Laboratory of 
Advanced Manufacture Technology for Automobile Parts (Chongqing University of Technology), Ministry of Education (grant No. 2019KLMT01); and the Graduate Student Innovation Program of Chongqing University of Technology (grant No. clgycx 20201003).

\section{References}

1. An J.C., Jing H.Y., Xu L.Y., Hu Q.G., 2011, Creep performance of HP40 alloy for ethylene cracking tube, Journal of Tianjin University (Science and Technology), 44, 10, 930-935

2. Brown W., Lim T.Y., 2017, Quantifying bolt relaxation during high temperature operation, ASME 2017 Pressure Vessels and Piping Conference, DOI: 10.1115/PVP2017-65550

3. Chen H.P., Zeng P., FAng G., Lei L.P., 2010, Load distribution of bolted joint, Journal of Mechanical Engineering, 46, 9, 171-178

4. Chen Y., Lu X., Jiang P., Guan Z.Q., 2017, Analysis on critical influential factors of axial load uniform distribution in bolted joint, Journal of Northeastern University (Natural Science), 38, 8, 1142-1147

5. Farrahi G.H., Chamani M., Reza K.K., Mostafazade A., Mahmoudi A.H., Afshin H., 2018, Failure analysis of bolt connections in fired heater of a petrochemical unit, Engineering Failure Analysis, 92, 327-342

6. Hantouche E.G., AL Khatib K.K., Morovat M.A., 2018, Modeling creep of steel under transient temperature conditions of fire, Fire Safety Journal, 100, SEP, 67-75

7. Hashimura S., Kamibeppu K., Nutahara T., Fukuda K., Miyashita Y., 2019, Effects of clamp force on fatigue strength of aluminum alloy bolts, Procedia Structural Integrity, 19, 204-213

8. Hou S.Y., LiaO R.D., 2015, Influence of ratcheting on self-loosening of bolted joints, Transactions of Beijing Institute of Technology, 35, 9, 924-930

9. Housari B.A., Nassar S.A., 2007, Effect of thread and bearing friction coefficients on the vibration-induced loosening of threaded fasteners, Journal of Vibration and Acoustics, 129, 4, 484-494

10. Thoppul S.D., Finegan J., Gibson R.F., 2009, Mechanics of mechanically fastened joints in polymer-matrix composite structures - A Review, Composites Science and Technology, 69, 3-4, 301-329

11. Wang X.Z., Hu S.W., 2017, Machine Design, Beijing Institute of Technology Press, Beijing

12. Welch M., 2018, Classical analysis of preloaded bolted joint load distributions, International Journal of Structural Integrity, 9, 4, 455-464

13. Xie Y.D., Xiao Y., Lv J.X., Zhang Z., Zhou Y.T., Xue Y.D., 2020, Influence of creep on preload relaxation of bolted composite joints: Modeling and numerical simulation, Composite Structures, 245, 112332

14. Zhang W.Z., Wei C.Y., Su Z.G., Liu J., Xiang J.H., 2003, A Study on forecasting of fatigue life for aluminium alloy piston of diesel engine, China Mechanical Engineering, 14, 10, 865-867

15. Zнао H., 1996, A numerical method for load distribution in threaded connections, Journal of Mechanical Design, 118, 2, 274-279

16. Zhou W.B., Zhang R.B., Ai S.G., He R,. Pei Y., FAng D., 2015, Load distribution in threads of porous metal-ceramic functionally graded composite joints subjected to thermomechanical loading, Composite Structures, 134, DEC, 680-688 